\title{
Effect of NP fertilizing on fruit yield and fruit quality of cactus pear
}

By

(1)Mohamed Arba, (2)Roger Paul, (3)Redouane Choukrallah, (4)André Falisse and (5)Marianne Sindic

(1) Plant Ecophysiology Laboratory, Hassan II Institute of Agronomy and veterinary Midecine (IAV Hassan II) - Horticultural Complex of Agadir,

Email: arbamohamed@yahoo.fr

(2) Environmental toxicology laboratory, Plant biology department Gembloux Agro Bio Tech, University of Liège, Belgium

(3) Salinity and Plant Nutrition Laboratory, IAV Hassan II - Horticultural

Complex of Agadir

(4) USAMV Cluj, Romania (and formerly Phytotechny of temperate regions department, Gembloux Agro Bio Tech, University of Liège, Belgium )

(5) QSPA laboratory, Department of Chimy, Gembloux Agro Bio Tech, University of Liège, Belgium. 


\section{INTRODUCTION}

some works are carried out on the metabolism and the physiology of cactus pear and on the effect of the environmental conditions on these aspects

Cactus pear is a species which seems to answer to fertilizers, in particular NP fertilizing

The application of fertilization in winter increased the production of floral buds in spring (Nerd and al., 1989 and 1991)

A great number of studies are done on the fertilization of cactus pear, mainly $\mathrm{N}$ fertilizer due to its effect on flowering.

Fruit quality is an important factor for human consumption and the marketing of fruits

The aim of this work was to study the effect of NP fertilizing on fruit yield and fruit quality 


\section{MATERIAL AND METHODS}

To response to the objectives of our study, we carried out experiment trials on the effect of some treatments of NP fertilizing on fruit yield and fruit quality of cactus pear.

Treatments of fertilization used are in $\mathrm{kgN}-\mathrm{P}_{2} \mathrm{O}_{5} / \mathrm{ha}$ ):

$-\mathrm{T} 1: 0 \mathrm{~N}-40 \mathrm{P}$

T3: $40 \mathrm{~N}-40 \mathrm{P}$

T5: $60 \mathrm{~N}-80 \mathrm{P}$

- T2: 0N-80P

T4: $60 \mathrm{~N}-0 \mathrm{P}$

The amounts of fertilizers used are similar to that used in some countries with climate like as Morocco (Italy, South Africa)

Fertilizers were involved in a drop irrigation system, they were applied between April and june in the 1st year of experiments (2010-2011) and between February and May in the $2^{\text {nd }}$ year experiments (2011-2012).

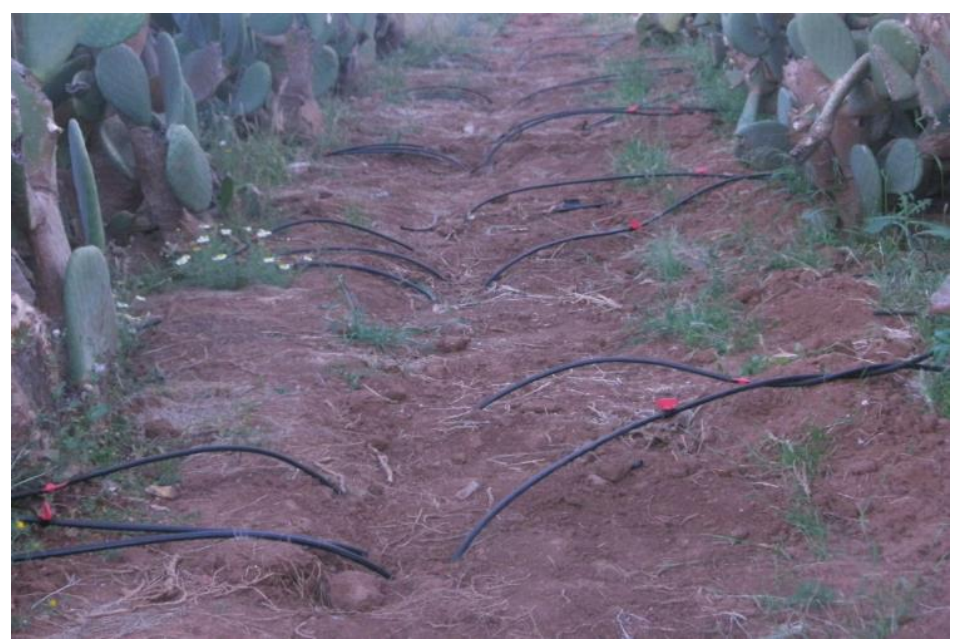


The plants were irrigated during the application of fertilizers on flowering and fruit development phases

Experiments were carried out at the experimental station of the Hassan II Institute of Agronomy and Veterinary Midecine, Horticultural Complexe of Agadir on an adult plantation of cactus pear cv 'Moussa'

The experimental design used was a complete randomized block

The qualitatif fruit characteristics studied focused on fruit size (weight and dimensions) A sample of 20 fruits by treatment of fertilization and by block was chosen.

For chemical analysises, a sample of 5 to 6 mixed fruits by treatment of fertilization and by block were chosen

Chemical analysises of the fruits focused on the rate of juice in pulp, the $\mathrm{pH}$ of juice, the acidity titrable, the Brix degree and total sugars. 


\section{RESULTS AND DISCUSSION}

Obtained results showed that fruit yield is higher in plants fertilized in $\mathrm{N}$ and fruit size is higher in plants fertilized in $\mathrm{P}$

In the 1st year (2010-2011), the fruits of T5 (60N-80P) have the best weight with $146,04 \mathrm{~g}$ and $79,07 \mathrm{~g}$ in pulp.

\begin{tabular}{|c|c|c|c|c|c|}
\hline & T1 & T2 & T3 & T4 & T5 \\
\hline Fruit lenght $(\mathrm{cm})$ & 7,26 & 7,4 & 7,59 & 7,35 & 7,49 \\
\hline Fruit diameter $(\mathrm{cm})$ & 5,29 & 5,33 & 5,36 & 5,24 & 5,47 \\
\hline Fruit weight $(\mathrm{g})$ & 132,48 & 141,79 & 141,59 & 134,35 & 146,04 \\
\hline Pulp weight $(\mathrm{g})$ & 72,74 & 75,59 & 75,66 & 72,15 & 79,07 \\
\hline Peel weight $(\mathrm{g})$ & 61,87 & 67,71 & 67,85 & 62,64 & 70,11 \\
\hline Peel thikness $(\mathrm{mm})$ & 1,83 & 2,08 & 2,21 & 1,96 & 2,06 \\
\hline
\end{tabular}


In the $2^{\text {nd }}$ year (2011-2012), the fruits of T5 (60N-80P) have the best size $(176,01 \mathrm{~g}$ in fruit weight and $8,27 \mathrm{~cm}$ in fruit lenght).

Fruits of the plants not fertilized are in the last raw with 120,67 $\mathrm{g}$ in fruit weight

\begin{tabular}{|c|c|c|c|c|c|}
\hline & T1 & T2 & T3 & T4 & T5 \\
\hline Fruit lenght (cm) & 7,08 & 7,77 & 7,74 & 7,72 & $\mathbf{8 , 2 7}$ \\
\hline Fruit diameter (cm) & 4,99 & 5,63 & 5,45 & 5,39 & 5,78 \\
\hline Fruit weight (g) & 120,67 & 160,24 & 150,48 & 148,39 & 176,01 \\
\hline Pulp weight (g) & 64,59 & 87,1 & 81,27 & 80,66 & 95,18 \\
\hline Peel weight (g) & 56,04 & 72,29 & 69,04 & 68,64 & 78,34 \\
\hline Peel thikness (mm) & 1,8 & 2,01 & 2,19 & 2,17 & 1,93 \\
\hline
\end{tabular}


Fruit yield and fruit size were higher in fertilized plants than in not or less fertilized.

In 2010-2011, Fruit yield was higher in T5 (20 kg /plant). It was $18 \mathrm{~kg} / \mathrm{plant}$ in T4, $17 \mathrm{~kg}$ in T1, and $14-15 \mathrm{~kg} / \mathrm{plant}$ in T2 and T3

In 2011-2012, fruit yield was significantly higher in T5 (32 kg /plant); it was $23 \mathrm{~kg} /$ plant in T4, $22 \mathrm{~kg}$ in T3, $20 \mathrm{~kg}$ in T2 and $17 \mathrm{~kg} / \mathrm{plant}$ in T1

In 2010-2011, soil and vegetal chemical analysises showed that in T5 the content of $\mathrm{N}$ in the pads was higher at the end of trials $(2,24 \%)$ than before the application of fertilizers $(1,75 \%)$,

and the content of $\mathrm{N}$ in the soil was also higher at the end of trials $(18,0 \mathrm{ppm})$ than before the application of fertilizers $(13,5 \mathrm{ppm})$

The content of $P$ in the soil of T5 was higher at the end of trials $(0,203 \%)$ as like as before the application of fertlizers $(0,224 \%$ )

But the content of $\mathrm{P}$ in the pads of $\mathrm{T} 5$ at the end of trials $(0,07 \%)$ and before the application of fertilizers $(0,06 \%)$ was almost similar. 
In 2011-2012, the content of $\mathrm{N}$ in the pads of T5 was also higher at the end of trials $(1,19 \%)$ than before the application of fertilization (1,05\%),

and the content of $\mathrm{N}$ in the soil of T5 was also higher at the end of trials $(25,9 \mathrm{ppm})$ than before the application of fertilizers (18,0 ppm)

Soil and pads chemical analysises of the 5 treatments of fertilization (T1, I2, T3, T4 and T5) in 2011-2012.

\begin{tabular}{|c|c|c|c|c|c|}
\hline \multicolumn{2}{|c|}{} & \multicolumn{2}{|c|}{ The content of N } & \multicolumn{2}{c|}{ The content of P } \\
\cline { 3 - 6 } \multicolumn{2}{|c|}{} & $\begin{array}{c}\text { In the pads } \\
(\%)\end{array}$ & $\begin{array}{c}\text { In the soil } \\
(\mathrm{ppm})\end{array}$ & $\begin{array}{c}\text { In the } \\
\text { pads (\%) }\end{array}$ & $\begin{array}{c}\text { In the } \\
\text { soil (\%o) }\end{array}$ \\
\hline \multirow{3}{*}{ T1 } & Before the application of fertilizers & 0,91 & 3,5 & 0,12 & 0,109 \\
\cline { 2 - 6 } & At the end of trials & 0,98 & 3,4 & 0,12 & 0,11 \\
\hline \multirow{3}{*}{ T2 } & Before & 0,98 & 7,9 & 0,12 & 0,275 \\
\cline { 2 - 6 } & At the end & 1,13 & 5,6 & 0,12 & 0,384 \\
\hline \multirow{3}{*}{ T3 } & Before & 1,05 & 11,2 & 0,12 & 0,181 \\
\cline { 2 - 6 } & At the end & 1,12 & 22,5 & 0,13 & 0,134 \\
\hline \multirow{3}{*}{ T4 } & Before & 1,05 & 14,6 & 0,13 & 0,108 \\
\cline { 2 - 6 } & At the end & 1,26 & 32,6 & 0,13 & 0,085 \\
\hline \multirow{3}{*}{ T5 } & Before & 1,19 & 25,9 & 0,14 & 0,331 \\
\cline { 2 - 6 } & At the end & 18,0 & 0,13 & 0,262 \\
\hline
\end{tabular}


Chemical anlysis of the fruits showed that the rate of juice in the fruits is different between treatments and the years of experiments due probably to harvesting and fruit ripening periods.

The ${ }^{\circ} \mathrm{Brix}$ and the acidity titratable were higher in the $2^{\text {nd }}$ year (2011-2012), but the $\mathrm{pH}$ and total sugars were lower in the same year in comparison with the 1st year (2010-2011).

\section{CONCLUSION}

Our work showed that NP fertilizing has increased the fruit yield and fruit quality, mainly the fruit size

As an economic important factor in the human consomption, fruit size is the important character of quality in the marketing criters of cactus pear fruits.

The application of other amounts of NP and in different periods of the year (in automn and in in winter) is necessary to complete our data on the fertilization of cactus pear

Application of other fertilizers, as $\mathrm{K}$ and $\mathrm{Mg}$ are also necessary to make an idea on the effect of other fertilizers on fruit yield and fruit quality of cactus pear,

in spite of some studies have reported that did not well respond to $\mathrm{K}$ fertilizer 